\title{
A CRIANÇA PRÉ-ESCOLAR: O NASCIMENTO DO SER SIMBÓLICO
}

\section{Fernando Lefèvre ${ }^{1}$}

LEFÈVRE, F. A Criança Pré-escolar: o nascimento do ser simbólico. R B. C. D. H. 1(1): São Paulo, 1991.

\section{RESUMO}

Trata-se, em grandes linhas, de relatar alguns aspectos do processo que se batizou de "nascimento do ser simbólico".

A hipótese é que a criança pré-escolar na faixa dos 2-6 anos, está nascendo como ser simbólico, como animal capaz de simbolizar, ou seja, manipular com seu corpo e sua mente as coisas que estão no mundo, como matéria significaste.

Uma vez nascido como ser simbólico, a criança institui-se como produtor/reprodutor de sentido.

A opção que se coloca para a Escola, neste momento, consiste, justamente, em se posicionar diante desta dialética produtor/reprodutor.

Dando-se ênfase à formação de um ser simbólico reprodutor dos sentidos pré-existentes na cultura, estaremos optando por uma educação socializadora, adaptadora.

Caso a ênfase esteja na formação de um ser simbólico produtor de sentido, estaremos optando por uma educação transforrnadora, dirigida para o uso criativo, pela criança, da sua competência simbolizaste.

\section{INTRODUÇÃO}

A idéia central desta exposição é a de que, na faixa etária dos 2 aos 6/7 anos, a criança está nascendo sirnbolicamente, ou seja, está nascendo para a vida simbólica, numa sociedade e numa culturas na medida em que, na criança, neste momento de vida, está se formando a capacidade de representar através de simbolos. Esta capacidade, formada, permitirá à criança estar aparelhada no final desta etapa para se constituir como um ser simbólico.

Quando se fala aqui em nascimento simbólico da criança, está se falando de um processo de nascimento cujo momento final é o nascimento propriamente dito. Deste modo, nascimento, neste contexto, pode ser entendido como sinônimo de gestação. Assim, nossa idéia é a de que, nesta faixa etária, está sendo gostado um ser simbólico.
Podemos então fazer uma analogia entre a vida pré-escolar e a vida intra-uterina. Com efeito, ambas são situações "pré". O ser humano, no útero materno, é um pré-organismo, é algo que está sendo construído; é portanto algo que não existe. No momento em que a criança sai do útero ela é um concepto, ou seja, um concebido, algo que existe. Este algo existente é um organismo que agora está apto a crescer e se desenvolver, enquanto organismo.

Da mesma forma, a criança na pré-escola é um ser simbolico em gestação. Ao término deste processo, temos também um existente, ou seja, um ser simbólico gostado, capaz, como o ser organico, de crescer e se desenvolver, enquanto ser sirnb61ico.

Na medida em que se sabe que o homem é um ser simbólico, que esta é uma característica distintiva do ser humano, pode se lançar a ideia

1 Professor-doutor do Departamento de Prftica de Saúde Pública da Faculdade de Saíde Pública da USP. 
que uma dimensão necessária do homem, enquanto espécie animal, está sendo gostada na fase préescolar.

Mais genericarnente, podemos avançar a idéia de que sendo o ser humano um ser biológico, um ser psicológico, um ser social e um ser simbolico, podemos conceber a existência, para cada uma destas dimensões, de processos de gestação, crescimento e desenvolvimento. Nessa linha de raciocínio, os processos de gestação seriam caracterizados pelo falo de neles estar se dando, sempre, a produção de algo. Nos processos de gestação temos sempre um "ainda não existente”, ou seja, uma matéria-prima sendo trabalhada para dar lugar, no final do processo de trabalho, a um produto, a um existente.

Se esta analogia da gestação com o processo produtivo é aceita, pode-se deduzir que a gestação interfere no produto final: um ser humano bem gostado biológica, psicológica e simbolicamente terá aumentadas as suas potencialidades de crescer e se desenvolver como entidade biológica (ou seja, enquanto orgarusmo), como entidade psicológica (ou seja, enquanto indivíduo), como entidade social (ou seja, enquanto animal político, da polis, da cidade) e como entidade simbolizante (ou seja, enquanto ser capaz de entender e agir sobre o mundo através das linguagens entendidas como sistemas simólicos).

Vamos, portanto, tentar colocar aqui algumas idéias preliminares sobre a gestação do ser simbólica, na suposição de que um processo deste tipo esteja ocorrendo na faixa etária correspondente ao período da pré-escola. Para isso, é necessário colocar uma característica muito geral de todo o processo simbolico.

Esta característica diz respeito ao falo de que simbolizar 6 representar, no sentido de que o que representa, o Dignificante, está “em nome do representado", do significado².

\section{Afirma Piaget:}

\footnotetext{
A função simbólica se explica pela formação de representações. Com efeito, o próprio da função simbólica consiste numa diferenciação dos significantes (signos ou simbolos) e dos significados. No terreno senso-motor já existem sistemas de dignificações (..). Mas o único significante que as condutas sensomotoras conhecem é o índice (em oposição aos signos e simbolos) ou o sinal (condutas condicionadas). Ora, o índice e o sinal são significantes relativamente indife-renciados de seus significados. Estes são apenas partes
}

\begin{abstract}
ou aspectos do significado e não representações que permitam a evocação (...). A formação da função simbólica consiste ao contrário em diferenciar as significantes dos significados, de modo que as primeiras permitam a evocação da representação dos segundos $^{3}$.
\end{abstract}

Segundo Piaget, temos, nessa idade, a formação da função simbólica, identificada com o ato de representar. Podemos então dizer, de acordo com nossa perspectiva, que nesta faixa etária está sendo gostado ou formado um ser humano como um ser simbólico, ou seja, um ser progressivamer e capaz de representar o mundo na sua ausência. O instrumento usado para representar o mundo na sua ausência são os simbolos e signos e os sistemas de signos que são as linguagens.

Piaget, na obra citada, tratando da faixa etária que estamos considerando, dá, como exemplo do símbolo criado por sua filha para representar a situação de dormir, o conjunto de significantes composto por: um pedaço de lençol fechado firmemente na mão da criança, mais o polegar na boca e mais os olhos fechados. Comentando este exemplo, coloca Piaget:

\begin{abstract}
Temos aí o exemplo de uma representação independente da linguagem, mas ligada a um símbolo lúdico, que consiste em gestos apropriados imitando os que acompanham comumente determinada ação. Ora, a ação assim representada não possui nada de presente ou atual, referindo-se a um contexto ou a uma situação apenas evocada, o que constitui a característica da representação (Op. Cit., pp. 84-85)
\end{abstract}

Temos basicamente dois grandes tipos de processos de representação: aqueles que envolvem conjuntos de significantes motivados e aqueles que envolvem conjuntos de significantes arbitrários ${ }^{4}$. Os conjuntos de significantes motivados guardam em si traços em comum com o que estão representando, com o significado. No exemplo dado por Piaget, os gestos e a chupeta guardam muitos traços em comum com o ato de dormir.

Os conjuntos de dignificantes arbitrários (as palavras da linguagem verbal, os signos lógico-matemáticos) não têm traços em comum com o que estão representando, com o significado. É claro, portanto, que o falo de os significantes arbitrários não manterem relações de dependência frente aos significados confere a estes significantes um poder representativo muito maior do que o

PIERCE, C. Semiótica c Filosofia. 2a ed., São Paulo, Cultrix/EDUSP, 1975.

PIAGET, J. Seis Edtudos de Psicologia. Rio de Janeiro, Forence, s.d., pp. 85-86.

4 TODOROF, S; et al. Linguagem e Motivação: uma pcrspectiva scmiológica. Porto Alegre, Globo, 1977. 
poder representativo dos significantes motivados. Este poder representativo maior implica uma independência cada vez maior do espaço e do tempo presente imediato, permitindo cada vez mais que o pensamento conforme o mundo.

Poderíamos entender, à luz da semiótica como ciência geral dos processos de dignificação, a faixa etária dos 2 aos 6/7 anos como implicando a manipulação, a experimentação com uma matéria-prima variadíssima (sons, traços, cores, argila, gostos, madeira, plástico, etc.) que pode ser vista como o que esta mesma semiótica chama de matéria significante ${ }^{5}$, ou seja, matéria-prima para a confecção de representações.

Na faixa etária dos 2 aos 6/7 anos, a atividade cognitiva de representar o mundo é uma forma ativa de dominá-lo através da atividade simbólica. A esta forma ativa e progressiva de dominar o mundo corresponde uma sensação forte de poder, em que a criança se sente, enquanto indivíduo, um ser capaz de recriar o mundo através do pensamento, da imaginação, da representação, em uma palavra, da atividade simbólica. Cremos que é decisivo, pedagogicamente, reforçar este sentimento, esta consciência do ser humano como um ser simb61ico. $\mathrm{O}$ reforço deste sentimento talvez possa ser visto como um dos princípios a guiar a intervenção pedagógica na faixa etária do pré-escolar.

Mas a atividade simbólica tem dois lados: um lado é o da dominação e o outro é o da adaptação. Com efeito, na medida em que a criança avança no processo da simbolização ela também vai tendo que se adaptar, ou seja, sujeitar-se à presença cada vez mais forte do código, ou seja, de regra, da norma, da gramática, que é característico dos sistemas simb61icos mais complexos.

A atividade representativa implica em aprimorar-se, o que é um ato de dominação, mas também em adaptar-se porque esta apropriação vai progressivamente perdendo a característica de ser uma apropriação do mundo como uma representação individual, voluntária, para ir se tornando a apropriação do mundo como uma representação coletiva ou social, dada pelas linguagens como formas codificadas ou regradas de se apropriar do mundo, e posteriormente pelos discursos produzidos por estas linguagens.

A questão filosófica que se coloca neste momento é a seguinte: o que resta desta atividade simbólica expontanea, individual, da criança, como criadora de simbolos e representações? Estaria ela condenada a ser evacuada como uma forma infantil, egocêntrica, de representar, em favor de formas regradas e sociais, mais elabo- radas, de representar? A resposta a esta indagação não é simples.

De um lado, é verdade que a linguagem (e os discursos feitos com esta linguagem) é a forma em que o social, o coletivo, acaba se impondo, necessariamente, sobre o individual, entendido como egocêntrico. Mas, se a linguagem e os discursos são, nesse sentido, imposição de uma forma de representar, é preciso ver de perto qual a natureza desta imposição.

Impor a indivíduos, através da linguagem ou dos símbolos socializados, o social como dimensão de ser humano é, na terminologia da psicologia, uma castração inevitável. Ou se se prefere a terminologia das ciências sociais, uma tarefa socializadora associada necessariamente à viabilização da vida humana sobre a terra. Ocorre que esta socialização é também, sempre, uma atividade ideológica, na medida em que a imposição do social acaba se confundindo com a imposição de um determinado modelo de organização da vida em sociedade.

Ora, é evidente que a linguagem e os discursos não são, em si, impositivos neste último sentido, ainda que se prestem—e muito—, dada a sua natureza Iminentemente coletiva, a este tipo de imposição. As linguagens e os discursos são representações coletivas, mas também são instru-

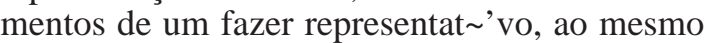
tempo individual e coletivo, ou seja, de um pensar, que transcende estas linguagens e discursos. E óbvio que com a mesma linguagem é possível representar o mundo das mais variadas maneiras.

O que é um ser simbó1ico? É um ser capaz de:

- Emitir representações, ou seja, falar, escrever, pintar, tirar fotografias, filmar;

- Consumir representações, ou seja, ler, ouvir, sentir, ver;

- Reproduzir representações, ou seja, tocar piano, cantar;

- Produzir e re-criar representações: atividade artística, ou filosófica, ou científica, criadora.

Um ser simb61ico capaz de emitir, consumir e produzir representações estará apto a viver em qualquer sistema social, que é sempre estruturado simbolicamente, ou seja, através de processos codificados de representações (ou seja, linguagens) e de produtos codificados destes processos (ou seja, discursos).

A opção filosófica que se coloca é que, dependendo do modelo de ser simbolico que se tenha, estimula-se ou não, na criança pré-escolar, a faculdade humana de produzir e re-criar representações.

5 VERON, E. A Produção do Sentido. São Paulo, Cultrix/EDUSP, 1980. 
Se se adota a política de estimular a faculdade humana de produzir e re-criar representações é que se acredita que, se de um lado o mundo do homem é uma vasta representação acumulada historicamente, um mundo já representado ao qual o homem como ser simbolico precisa acomodar-se, é também, por outro lado, um permanente a-representar já que a representação é um processo histórico e o homem um produtor nato de representações. Portanto, num processo, cremos, adequado de acompanhamento da gestação do ser simbolico, é preciso que nele esteja desenvolvida uma capacidade de apropriação crítica e criadora do já dominado historicamente (linguagens e discursos) que recupere faculdade humana de criar representações. Ora, esta faculdade é algo que brota expontaneamente na faixa etária que estamos considerando. É necessário aproveitar esta circunstância peculiar. Para tanto é preciso desenvolver uma pedagogia que dê conta das polaridades apostas da dominação e da acomodação.

Ó homem é um ser simb61ico criativo enquanto entidade individual e enquanto entidade

\section{BIBLIOGRAFIA}

PIAGET, J. Seis Estudos de Psicologia. Rio de Janeiro, Forense, 1978.

PIERCE, C. S. Semiótica e Filosofia, 2a ed., São Paulo, Cultrix/EDUSP, 1975. sócio-histórica. É preciso reconciliar estas duas vertentes do ser simbolico criativo. O período préescolar do qual tratamos parece ser uma oportunidade para realizacão desta reconciliarão. Nesse sentido, podemos pensar que uma forma de efetuar esta reconciliação sena através da associac,ão entre o jogo, a fantasia, a imaginação e os $\mathrm{s} \sim \mathrm{rnbolos}$ e as linguagens. Isto é evidentemente possível de ser feito porque os sfmbolos e as linguagens podem perfeitamente ser pensados como peças do jogo simbólica, ou seja, do jogo de pensar, do jogo de imaginar, do jogo de representar. Assim, este jogo simbolico (de que fala Piaget) poderia ser repensado e deixar de ser considerado como uma mera etapa, um mero momento genético a ser ultrapassado, para vir a se constituir um princípio a ser seguido na formação do ser simbolico.

Para isso é preciso optar filosoficamente pela associação ao homo cogitans carteziano, ao homem que "pensa, logo existe", o borne ludens, para que dessa associação nasça o homem que brinca de pensar.

TODOROF, S. et al. Linguagem e Motivação: uma perspectiva semiológica. Porto Alegre, Globo, 1977.

YERON, E. A Produção do Sentido. São Paulo, Cultrix/EDUSP, 1980. 